[Agr. Biol. Chem., Vol. 32, No. 9, p. 1103 1107, 1968]

\title{
Isolation of 6-Hydroxydehydroabietinol and Hinokiol from the Leaves of Torreya nucifera Sieb. et Zucc.*
}

\author{
By Isao Fukushima, Yoshikatsu Sayama, Kazuaki Kyogoku, \\ and Hiroshi Murayama \\ Research Laboratory, Taisho Pharmaceutical Co., Ltd. \\ No. 34-1, Takata 3-chome, Toshima-ku, Tokyo
}

Received March 15, 1968

\begin{abstract}
6-Hydroxydehydroabietinol and hinokiol were isolated from the non-steam-volatile fraction of the leaves of Torreya nucifera Sieb. et Zucc. (Taxaceae) (Japanese name "Kaya"). The former was also isolated from the immature fruits of the same plant. This is the first report of the isolation of 6-hydroxydehydroabietinol from a natural source. This compound was prepared previously and reported to show marked estrogenic activity.
\end{abstract}

Previous works on the leaf constituents of Torreya nucifera Sieb. et Zucc. (Taxaceae) (Japanese name "Kaya") have dealt with the volatile compounds, ${ }^{1-31}$ waxes, ${ }^{41}$ and kayaflavone. ${ }^{5}$ In this paper we report the investigation on the non-steam-volatile constituents of the leaves. Fresh leaves were extracted with boiling methanol, and the volatile constituents of the extract were removed by steam distillation. The residual<smiles>[R1]c1cc2c(cc1C(C)C)CCC1C([R1])([R1])CCCC21C</smiles><smiles>CC(C)c1cc2c(cc1O)[C@]1(C)CCC(O)[C@H](C)[C@H]1CC2</smiles>

II<smiles>[R]O[R]([R])=O</smiles>

2) K. Nishida and H. Uota, ibid., 43, 150 (1940). 3) T. Sakai, K. Nishimura, H. Chikamatsu and Y. Hirose, Bull. Chem. Soc. Japan, 36, 1261 (1963). 4) H. Watanabe, Yakugaku Zasshi, 73, 176 (1953) 5) T. Kariyone and T. Sawada, ibid., 78, 1010 (1958).

\footnotetext{
* This work was presented at the 11th Symposium on Chemistry of Terpenes, Essential Oil and Aromatics at Matsuyama, Oct. 20, 1967.

1) E. Shinozaki, Kogyo Kagaku Zasshi, 25, 768 (1922).
} 
resin-like material was extracted with boiling ether and then boiling ethyl acetate. The neutral fraction of the combined extracts was chromatographed on a silica gel column (dry column method) and separated into four portions; 1, 2, 3, and 4 as shown in Fig. 1.

The portion 2 gave a crystalline compound, A (Ia), $\mathrm{C}_{20} \mathrm{H}_{30} \mathrm{O}_{2}$, which afforded diacetate with acetic anhydride and pyridine, thus accounting for both oxygene functions as hydroxyl groups. The ultraviolet spectra of $A$ and its diacetate were very similar to those of hinokiol (II), isolated from the portion 3,

TaBLE I. NMR Data of HiNokiol Diacetate AND A DIACETATE (IN $\mathrm{CDCl}_{3}, \delta$-VALUE)

\begin{tabular}{|c|c|c|}
\hline $\begin{array}{l}\text { Hinokiol } \\
\text { diacetate }\end{array}$ & $\begin{array}{c}\text { A } \\
\text { diacetate }\end{array}$ & Assignment* \\
\hline 0.94 & 0.94 & $\mathrm{C}_{1}-\mathrm{CH}_{3}$ \\
\hline 1.18 & 1.17 & $\begin{array}{c}\mathrm{C}_{7} \quad \mathrm{CH}\left(\mathrm{CH}_{3}\right)_{2}, J=6.9,6.0 \\
\text { cps, respectively }\end{array}$ \\
\hline 1.21 & $\begin{array}{l}1.22 \\
2.03\end{array}$ & $\begin{array}{l}\mathrm{C}_{12}-\mathrm{CH}_{3} \\
\mathrm{C}_{1}-\mathrm{CH}_{2} \mathrm{OCOCH}_{3}\end{array}$ \\
\hline 2.08 & & $\mathrm{C}_{2}-\mathrm{OCOCH}_{3}$ \\
\hline 2.31 & 2.29 & $\mathrm{C}_{6}-\mathrm{OCOCH}_{3}$ \\
\hline 2.92 & 2.85 & $\underset{\text { multiplet }}{\mathrm{C}_{7}-\mathrm{CH}\left(\mathrm{CH}_{3}\right)_{2}}$ and $\mathrm{C}_{9}-\mathrm{H}_{2}$, \\
\hline & $\begin{array}{l}3.56,3.74 \\
3.92,4.11\end{array}$ & $\begin{array}{l}\mathrm{C}_{1}-\mathrm{CH}_{2} \mathrm{OAc} \text {, symmetrical } \\
\mathrm{AB} \text { quartet }\end{array}$ \\
\hline 4.56 & & $\mathrm{C}_{2}-\mathrm{H}$ (broad) \\
\hline 6.81 & 6.81 & aromatic protons \\
\hline 6.95 & 6.93 & \\
\hline
\end{tabular}

* Assignment of peaks follows published data on ferruginol diacetate (Hitachi Model H-60 High Resolution NMR Spectrometer Data Issue, Serial No. 20) and related compounds.

and its diacetate, respectively. The NMR spectrum of A diacetate was also substantially similar to that of hinokiol diacetate except that in the former a $0.94 \delta$ gem-dimethyl peak observed in the latter is replaced by a $0.94 \delta$ methyl peak and an $\mathrm{AB}$ quartet centered at $3.83 \delta$, and that a $4.56 \delta \mathrm{C}-2$ proton peak of the latter is absent (Table I). Dehydrogenation of A with selenium gave a crystalline compound with the same melting point and molecular formula as 6-hydroxyretene (III) ${ }^{61}$

6) J. L. Simonsen and D. H. R. Barton, "The Terpenes," Vol. III, Cambridge University Press, 1961, p. 355 and 365 . which has been obtained on the same treatment of ferruginol (Ie) and hinokiol. On treatment with dimethyl sulfate and potassium hydroxide in boiling acetone, A furnished a monomethyl ether (Ib). Oxidation of the monomethyl ether with chromium trioxide gave an aldehyde (Ic). Thus, one of the hydroxyl groups in A is phenolic, and the other is primary alcoholic.

These characters suggest that A may be 6hydroxydehydroabietinol (Ia) or 7-isopropylpodocarpinol (Id) as shown in Table II. In the NMR spectrum of A diacetate the two

TABLE II. CoMparison OF THE Physical CONSTANTS

\begin{tabular}{|c|c|c|c|}
\hline & A & Ia & Id \\
\hline $\mathrm{mp}\left({ }^{\circ} \mathbf{C}\right)$ & $180 \sim 1$ & $180 \sim 1.5^{8}$ & $185.4 \sim 6.410$ \\
\hline $\begin{array}{l}{[\alpha]_{\mathrm{D}}^{25}(\text { in } \mathrm{EtOH})} \\
\mathrm{mp}\left({ }^{\circ} \mathrm{C}\right) \text { of derivs. }\end{array}$ & $+70.3^{\circ}$ & $+72^{\circ}$ & \\
\hline $\begin{array}{l}\text { Monomethyl } \\
\text { ether }\end{array}$ & 86 & & $83 \sim 8510\}$ \\
\hline $\begin{array}{l}\text { Monomethyl } \\
\text { aldehyde }\end{array}$ & $137 \sim 8$ & $137 \sim 8 *$ & $136 \sim 6.5^{*}$ \\
\hline (Semicarbazone) & $\begin{array}{c}234 \sim 5 \\
\text { (decomp.) }\end{array}$ & $236 \sim 7 *$ & $\begin{array}{r}113 \sim 120^{*} \\
\text { (impure) }\end{array}$ \\
\hline
\end{tabular}

methylene protons of the C-1 acetoxymethyl group form an $\mathrm{AB}$ system where $H_{\mathrm{A}}=3.68 \delta$, $H_{\mathrm{B}}=4.00 \delta, \delta_{\mathrm{AB}}=19.0 \mathrm{cps}$, and $J_{\mathrm{AB}}=11.0 \mathrm{cps}$. In $\mathrm{A}$ monomethyl ether this $\mathrm{AB}$ system shows up as peaks centered at about $3.20 \delta$ which are overlapped with the others. These values are very close to those recorded by Wenkert and Beak $^{7 /}$ for equatorial acetoxymethyl and hydroxymethyl groups at C-1 in similar compounds. Therefore, A appeared to be identical with 6-hydroxydehydroabietinol. Finally, this compound was partially synthesized from dehydroabietic acid (If) according to the method given by Fieser and Campbell. ${ }^{81}$ The direct comparison confirmed the identity of $A$

7) E. Wenkert and P. Beak, Tetrahedron Letters, $1961,358$.

8) L. F. Fieser and W. P. Campbell, J. Am. Chem. Soc., 61, 2528 (1939). 
with 6-hydroxydehydroabietinol. Both compounds $\mathrm{Ia}^{8,9)}$ and $\mathrm{Id}^{101}$ were previously partially synthesized and found to have considerable estrogenic activity. 6-Hydroxydehydroabietinol was also isolated from the immature fruits of the same plant. This is the first discovery of 6-hydroxydehydroabietinol in a natural source.

A diterpene phenol, $\mathrm{B}, \mathrm{C}_{20} \mathrm{H}_{30} \mathrm{O}_{2}$ was also isolated by further chromatography from the portion 3, and this compound was identified as hinokiol by direct comparison with an authentic sample. Hinokiol has been isolated from the wood of several species of Taxodiaceae and Cupressaceae but not from the leaves.

\section{EXPERIMENTAL}

Meting points were uncorrected. Optical rotations were measured with a Yanagimoto Recording Spectropolarimeter Model ORD-185. UV spectra were recorded on a Hitachi Recording Spectrophotometer EPS-2U type. IR spectra were recorded on a JASCO DS-301 spectrophotometer. NMR spectra were determined at $60 \mathrm{Mc}$. in $\mathrm{CDCl}_{3}$ solutions (unless otherwise stated) containing tetramethylsilane as an internal standard using a JNM C-60 spectrophotometer.

Chromatography was carried out by a dry column method with silica gel unless otherwise stated.

Isolation of the compounds $A$ (6-hydroxydehydroabietinol) and $B$ (hinokiol). Fresh leaves of Torreya nucifera (15 kg) which were collected at Kida-gun in Shizuoka prefecture, Jul., 1966 were extracted 3 times with boiling $\mathrm{MeOH}(90,30$, and 30 liter). The combined extract was concentrated under reduced pressure to 10 liter and filtered. The filtrate was further concentrated to 2 liter, which was then steam distilled until 11 liter of the distillate was obtained. Decantation of the residue gave a dark colored resin-like material, which was repeatedly extracted with boiling ether and then boiling AcOEt. The combined extract in ether was washed with saturated $\mathrm{NaHCO}_{3}$ and then by $5 \%$ $\mathrm{NaOH}$ solution in the usual manner. The washed extracts afforded $60 \mathrm{~g}$ of a reddish brown syrup.

Forty grams of this neutral fraction was chromato-

9) R. N. Moore and R. V. Lawrence, ibid., 81, 458 (1959).

10) M. M. Baizer, M. Karnowsky, and W. G. Bywater, ibid., 72, 3800 (1950). graphed on a silica gel column $(5 \times 114 \mathrm{~cm})$ with hexane-ether and separated into four portions $(1,2$, 3 , and 4 ; fraction No. 1-7, 8-22, 23-29, and 30-40, respectively) as shown in Fig. 1. The yields of each portion, $1,2,3$, and 4 , were $16.1 \mathrm{~g}$ (reddish brown

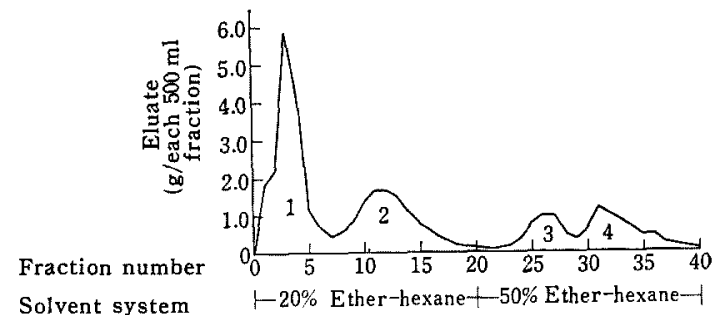

FIG. 1. Chromatography of the Neutral Fraction on a Silica Gel Column $(5 \times 114 \mathrm{~cm})$.

syrup), $10.9 \mathrm{~g}$ (yellow crystalline material), $3.9 \mathrm{~g}$ (dark green crystalline material), and $5.5 \mathrm{~g}$ (dark green crystalline material), respectively.

(a) Portion 2 (17 g) was repeatedly recrystallized from acetone or $\mathrm{EtOH}$-hexane to give $15 \mathrm{~g}$ of $\mathrm{A}$ (yield, $0.1 \%$ to fresh matter of the leaves), mp $180 \sim$ $181^{\circ} \mathrm{C}$. $\quad[\alpha]_{\mathrm{D}}^{25}+70.3^{\circ}(c=0.37, \mathrm{EtOH})$. Anal. Found: C, 79.13; $\mathrm{H}, 9.79$. Calcd. for $\mathrm{C}_{20} \mathrm{H}_{30} \mathrm{O}_{2}$ : C, 79.42; $\mathrm{H}, 10.00 \% \cdot \lambda_{\mathrm{aY}}^{\mathrm{MeOH}} \mathrm{m} \mu(\log \varepsilon): 283.5(3.45) \cdot \nu_{\mathrm{max}}^{\mathrm{KBr}} \mathrm{cm}^{-1}$ : $3460,3240(\mathrm{OH}), 1618,1582,1510$ (aromatic $\mathrm{C}=\mathrm{C}$ ), $1385,1375,1174,1138$ (isopropyl group).

The diacetate of $A$ was prepared by treatment with pyridine-acetic anhydride (overnight at room temperature). Purification by chromatography with $5 \%$ ether in hexane yielded colorless oil. Anal. Found: C, 74.68; $\mathrm{H}, 8.52$. Calcd. for $\mathrm{C}_{24} \mathrm{H}_{34} \mathrm{O}_{4}$ : C, $74.57 ; \mathrm{H}, 8.87 \%$. $\lambda_{\mathrm{max}}^{\mathrm{MeOH}} \mathrm{m} \mu(\log \varepsilon): 269$ (3.04), 277 (3.08). $\nu_{\max }^{\text {film }} \mathrm{cm}^{-1}: 1760,1740,1240,1210$.

(b) Portion $3(6 \mathrm{~g})$ afforded a crystalline compound after rechromatography with $5 \%$ acetone in hexane, which was repeatedly recrystallized from acetone or EtOH to give about $1 \mathrm{~g}$ of B (yield, 0.007\%), mp $233 \sim 235^{\circ} \mathrm{C} . \quad[\alpha]_{\mathrm{D}}^{25}+67.3^{\circ} \quad(c=0.55, \quad \mathrm{EtOH})$. Anal. Found: $\mathrm{C}, 79.20 ; \mathrm{H}, 10.02$. Calcd. for $\mathrm{C}_{20} \mathrm{H}_{30} \mathrm{O}_{2}$ : C, $79.42 ; \mathrm{H}, 10.00 \% . \quad \lambda_{\mathrm{max}}^{\mathrm{MeOH}} \mathrm{m} \mu(\log \varepsilon): 283.5$ (3.51). $\nu_{\mathrm{KBr}}^{\mathrm{KBr}} \mathrm{cm}^{-1}: 3540,3300(\mathrm{OH}), 1612,1581,1510$ (aromatic $\mathrm{C}=\mathrm{C}$ ), 1378, 1370, 1168, 1138 (isopropyl group). The diacetate was prepared in the same way as described above. Recrystallization from EtOH yieled colorless prisms, mp $142.5 \sim 143^{\circ} \mathrm{C}$. Anal. Found: C, 74.90; H, 9.14. Calcd. for $\mathrm{C}_{24} \mathrm{H}_{34} \mathrm{O}_{4}: \mathrm{C}, 74.57$; H, 8.87\%. $\lambda_{\max }^{\mathrm{MeOH}} \mathrm{m} \mu(\log \varepsilon): 269(3.10), 277$ (3.15). 
$\nu_{n A^{\circ}}^{\mathrm{KBr}} \mathrm{cm}^{-1}: \quad 1753,1727,1243,1210$. The mixed melting points of $\mathbf{B}$ and its diacetate with hinokiol and its diacetate, respectively were undepressed. Their infrared spectra were identical with those of authentic materials.

(c) The compound A was also isolated from the immature fruits of Torreya nucifera as follows. The immature fruits (about $150 \mathrm{~g}$ ) collected at the same time as the leaves were crushed and extracted 2 times with $400 \mathrm{ml}$ portions of boiling $\mathrm{MeOH}$. The extract was concentrated under reduced pressure and the concentrate was steam distilled until 1.2 liter of distillate was obtained. The residual solution was saturated with $\mathrm{NaCl}$ and extracted with ether. Evaporation of the ether afforded $7.4 \mathrm{~g}$ of a green syrup. The ether solution of this syrup was washed with saturated $\mathrm{NaHCO}_{3}$ followed by $5 \% \mathrm{NaOH}$ solution to yield $6 \mathrm{~g}$ of the neutral fraction. Three grams of the neutral fraction was chromatographed (wet column method) on a silicic acid column $(3 \times$ $36 \mathrm{~cm}$ ) with $\mathrm{CHCl}_{3}$. The compound $A$ was found in the $350 \sim 550 \mathrm{ml}$ fractions of the effluent. Treatment with charcoal followed by crystallization from acetone afforded $0.5 \mathrm{~g}$ of pure compound A (total yield, $0.67 \%$ to fresh matter of fruits).

Dehydrogenation of $A$ with selenium. The compound A ( $960 \mathrm{mg}$ ) was heated with selenium $(2.9 \mathrm{~g})$ at $290 \sim 310^{\circ} \mathrm{C}$ for $23 \mathrm{hr}$. Extraction of the cooled mixture with ether yielded a reddish brown syrup, which gave a crystalline compound $(240 \mathrm{mg}$ ) after chromatography with $3 \%$ ether in hexane. This was recrystallized several times from benzene-hexane to yield thin colorless flakes, $\mathrm{mp} 178.5 \sim 179.5^{\circ} \mathrm{C}$. Anal. Found: C, 86.64; $\mathrm{H}, 7.40$. Calcd. for $\mathrm{C}_{18} \mathrm{H}_{18} \mathrm{O}$ : C, 86.36; H, 7.25\%. $\lambda_{\max }^{\text {cyclotexane }} \mathrm{m} \mu(\log \varepsilon): 220.5$ (4.44), 258 (4.72), $278(4.26), 295$ (4.01), 307.5 (4.11), 323.5 (3.02), $339.5(3.29), 356.5$ (3.35), shoulder peak 283 (4.16). These characters were in agreement with those of 6-hydroxyretene stated in the literature.11)

Preparation of monomethyl ether of $A$. To the solution of $A(536 \mathrm{mg})$ in boiling acetone $(20 \mathrm{ml})$ were alternately added in portions, $25 \% \mathrm{KOH}$ solution $(1.5 \mathrm{ml})$ and dimethyl sulfate $(\mathrm{lg})$ over a period of $4 \mathrm{hr}$. The reaction mixture was filtered, and the filtrate was diluted with water. The solution was extracted with ether after evaporation of the acetone. The ether residue (yellow syrup) was purified by

11) C. W. Brandt and L. G. Neubauer, J. Chem. Soc., 1939, 1031; W. P. Campbell and D. Todd, J. Am. Chem. Soc., 62, 1287 (1940). chromatography with $5 \%$ ether in hexane to yield colorless oil of monomethyl ether $(474 \mathrm{mg})$. This oil was crystallized from petroleum ether to yield white crystals, $\mathrm{mp} 85.5 \sim 86^{\circ} \mathrm{C}$. NMR (in $\mathrm{CCl}_{4}$ ) $\delta$ : 6.69 and 6.58 ( $1 \mathrm{H}$ each, singlets, two para aromatic protons $), 3.74\left(3 \mathrm{H}\right.$, singlet, $\left.-\mathrm{OCH}_{3}\right), 1.18(3 \mathrm{H}$, singlet, $\left.\mathrm{C}_{12}-\mathrm{CH}_{3}\right), 1.13(6 \mathrm{H}$, doublet, $J=6.0 \mathrm{cps},-$ $\left.\mathrm{CH}\left(\mathrm{CH}_{3}\right)_{2}\right), 0.78\left(3 \mathrm{H}\right.$, singlet, $\left.\mathrm{C}_{1}-\mathrm{CH}_{3}\right)$. An $\mathrm{AB}$ quartet expected for the methylene hydrogens of $\mathrm{C}_{1}$ $-\mathrm{CH}_{2} \mathrm{OH}$ existed as peaks centered at about $3.20 \delta$ which are overlapped with the others. Anal. Found: $\mathrm{C}, 80.05 ; \mathrm{H}$, 9.87. Calcd. for $\mathrm{C}_{21} \mathrm{H}_{32} \mathrm{O}_{2}: \mathrm{C}, 79.70$; $\mathrm{H}, 10.19 \%$.

Oxidation of the monomethyl ether of $A$ with chromium trioxide. The monomethyl ether of A $(1.77 \mathrm{~g})$, dissolved in acetone $(20 \mathrm{ml})$ was treated with an oxidizing reagent $\left.{ }^{12}\right)(1.8 \mathrm{~g})$, prepared from chromium trioxide $(13.62 \mathrm{~g})$, water $(50 \mathrm{ml})$, and conc. sulfuric acid $(11 \mathrm{ml})$. The reaction mixture was poured into water and extracted with ether. The ether layer was washed with $10 \% \mathrm{NaOH}$ solution. Evaporation of the ether gave a crystalline residue $(1.53 \mathrm{~g})$, which was recrystallized from EtOH to yield an aldehyde (Ic) $(1.04 \mathrm{~g})$ as scales, $\mathrm{mp} 137 \sim$ $138^{\circ} \mathrm{C}$. NMR $\delta: 9.32$ ( $1 \mathrm{H}$, singlet, - CHO), 6.88 and 6.75 (1H each, singlets, two para aromatic protons), $3.83\left(3 \mathrm{H}\right.$, singlet, $\left.-\mathrm{OCH}_{3}\right), 3.26(1 \mathrm{H}$, quintuplet, $\left.J=6.8 \mathrm{cps},-\mathrm{CH}\left(\mathrm{CH}_{3}\right)_{2}\right), 2.83(2 \mathrm{H}$, complex multiplet, $\mathrm{C}_{9}$ methylene protons), $1.26(3 \mathrm{H}$, singlet, $\left.\mathrm{C}_{12}-\mathrm{CH}_{3}\right), 1.20\left(6 \mathrm{H}\right.$, doublet, $\left.J=6.8 \mathrm{cps},-\mathrm{CH}\left(\mathrm{CH}_{3}\right)_{2}\right)$, 1.17 (3H, singlet, $\mathrm{C}_{1}-\mathrm{CH}_{3}$ ). Anal. Found: C, 80.61; $\mathrm{H}, 9.35$. Calcd. for $\mathrm{C}_{21} \mathrm{H}_{30} \mathrm{O}_{2}$ : C, 80.21; H, 9.62\%. The semicarbazone crystallized from $\mathrm{MeOH}$ as needles, mp $234 \sim 235^{\circ} \mathrm{C}$ (decomp.). Anal. Found: C, 70.79; $\mathrm{H}, 8.98 ; \mathrm{N}, 11.37$. Calcd. for $\mathrm{C}_{22} \mathrm{H}_{33} \mathrm{~N}_{3} \mathrm{O}_{2}: \mathrm{C}$, $71.12 ; \mathrm{H}, 8.95 ; \mathrm{N}, 11.31 \%$.

Partial synthesis of 6-hydroxydehydroabietinol. 6-Hydroxydehydroabietinol was prepared from dehydroabietic acid (If) in the same way as described by Fieser and Campbell,8) except for the last step where methyl 6-hydroxydehydroabietate was treated with $\mathrm{LiAlH}_{4}$ instead of attempting high pressure hydrogenation. Total yield was $23 \%$, mp $180 \sim 181^{\circ} \mathrm{C}$. Anal. Found: $\mathrm{C}, 79.35 ; \mathrm{H}, 9.85$. Calcd. for $\mathrm{C}_{20} \mathrm{H}_{30} \mathrm{O}_{2}$ : C, $79.42 ; \mathrm{H}, 10.00 \%$. Mixed melting point determination of $A$ and 6-hydroxydehydroabietionl thus obtained was carried out, and no depression was observed. Their infrared spectra were superimposable.

12) R. H. Bible, Tetrahedron, 11, 22 (1960). 
Acknow ledgement. The authors wish to Munakata, Dr. S. Marumo, and Dr. N. Kato, express their sincere thanks to Dr. Y. Hirose, Nagoya University and to Dr. I. Tanaka, Tokyo University and to Dr. A. Tahara, The Director of this laboratory for their encourageInstitute of Physical and Chemical Research ment. They are also grateful to S. Uehara, for their kind advices and also for their kind President of this company for his permission supplies of hinkiol and dehydroabietic acid, to publish this paper.

respectively. Thanks are due to Prof. K. 